\title{
Ruling out nosocomial transmission of Cryptosporidium in a renal transplantation unit: case report
}

\author{
J. Brunet ${ }^{1,2^{*}}$, J. P. Lemoine ${ }^{1}$, B. Pesson ${ }^{1}$, S. Valot ${ }^{3}$, M. Sautour ${ }^{3,4}$, F. Dalle ${ }^{3,4}$, C. Muller $^{5}$, C. Borni-Duval ${ }^{5}$, S. Caillard ${ }^{5}$, \\ B. Moulin ${ }^{5}$, A. W. Pfaff ${ }^{1,2}$, R. Razakandrainibe ${ }^{6}$, A. Abou-Bacar ${ }^{1}$, L. Favennec ${ }^{6}$ and E. Candolfi, ${ }^{1,2}$
}

\begin{abstract}
Background: Cryptosporidium spp. is a ubiquitous parasite affecting humans as well as domestic and wild vertebrates, causing diarrhea in both immunocompetent and immunocompromised hosts worldwide. Its transmission occurs primarily by the fecal-oral route. In humans, C. parvum and C. hominis are the most prevalent species, whereas immunocompetent and immunocompromised individuals can also be infected by other zoonotic species. Renal transplant patients are prone to develop cryptosporidiosis, which can induce severe and life-threatening diarrhea.

Case presentation: We report here a series of nearly concomitant cases of acute symptomatic cryptosporidiosis in three renal transplant patients attending the Strasbourg University Hospital Nephrology Unit. The clinical presentation was persistent diarrhea and acute renal failure. The diagnosis was confirmed by microscopic stool examination using a modified Ziehl-Neelsen staining method and species identification by molecular tools. All patients were treated with nitazoxanide and recovered from diarrhea after 14 days of therapy.
\end{abstract}

Conclusion: Genotypic species identification was not consistent with an epidemic context, thus underlining the need for genotyping to monitor at risk patients.

Keywords: Cryptosporidium, Renal transplant, Zoonotic species, Genotypic species identification, Case report

\section{Background}

The coccidian protozoan Cryptosporidium spp. is an intestinal parasite and a significant cause of enteric disease in humans and numerous other vertebrates worldwide. Cryptosporidiosis is the most common zoonotic cause of human parasitic diarrhea (i.e., $60 \%$ of epidemic cases linked to waterborne and 2-6\% of cases involving severe diarrhea worldwide), especially in immunocompromised individuals and young children [1]. The latter is notably the case in developing countries, where this parasite ranks second in the causes of death in children under 2 years $[1,2]$. The prevalence of Cryptosporidium

\footnotetext{
* Correspondence: jbrunet@unistra.fr

'Laboratoire de Parasitologie et de Mycologie Médicale, Plateau Technique de Microbiologie, Hôpitaux Universitaires de Strasbourg, 1 place de l'Hôpital, BP 426, F-67091 Strasbourg cedex, France

${ }^{2}$ Institut de Parasitologie et Pathologie Tropicale, EA 7292, Fédération de Médecine Translationnelle, Université de Strasbourg, 3 rue Koeberlé, F-67000 Strasbourg, France

Full list of author information is available at the end of the article
}

in stools of immucompetent persons was found to be lower in high-income countries than in developing regions [3]. Infection occurs by oocyst-stage ingestion via contaminated drinking water, food or recreational waters, as well as by direct or indirect human-to-human or animal-to-human contact [4]. In France, 407 cases of cryptosporidiosis were diagnosed between 2006 and 2009 [5]. A study conducted by the Strasbourg University Hospital between 2011 and 2013 detected Cryptosporidium spp. in $2.4 \%$ of stools in which parasites have been detected out of a total of 6515 analyzed stools [6]. Over the past 20 years, three cryptosporidiosis outbreaks have been reported in France [5]. Other documented cases are linked to outdoor activity, swimming pools, day-care centers, and travel [3, 7]. Cryptosporidiosis can spread also among hospitalized patients and hospital staff and nosocomial outbreak of Cryptosporidium have been described. Source of infection could be 
contaminated water or contact with the hands of infected people $[8,9]$.

The increasing frequency of human cryptosporidiosis outbreaks raises relevant public health and economic concerns [10-12]. Human cases are commonly due to two species: $C$. hominis, which primarily infects humans, and C. parvum, which infects both humans and animals. Occasional infections by other species/genotypes, such as C. felis, C. meleagridis, C. canis or chipmunk and rabbit genotypes have been primarily reported in immunodeficient patients [5]. C. hominis and the zoonotic Cryptosporidium species are associated with a variety of clinical manifestations in humans [13].

The severity and duration of human Cryptosporidium infections are linked to the host's immune status [14]. Immunocompetent patients experience self-limiting disease, while in immunosuppressed patients, especially those with T-cell deficiency, cryptosporidiosis is often chronic and severe with risks of extra-intestinal disease development [15].

In renal transplant patients, post-transplant cryptosporidiosis with diarrhea is a frequent complication [16]. In France, 69.3 \% of clinically apparent cryptosporidiosis cases reported from 2006 to 2009 involved immunocompromised patients and $16.5 \%$ of them were reported in patients who had received solid-organ or stem-cell transplants [5]. One report from a pediatric renal transplant unit demonstrated that infections were the primary cause of diarrhea, with Cryptosporidium spp. diagnosed in $11 \%$ of 199 cases [3].

We report here three Cryptosporidium spp. infections with acute diarrhea and abdominal pain, observed almost simultaneously in three renal transplant patients who were subject to species genotyping in order to investigate a potential epidemic context in an outpatient nephrology unit.

\section{Case presentation}

The three cases were diagnosed in the outpatient unit of the Nephrology Department at Strasbourg University Hospital, France.

\section{Clinical histories}

Patient \#1 was a 60 -year-old man who underwent transplantation at the age of 52 for chronic renal failure due to polycystic kidney disease. He initially received immunosuppressive treatment, consisting of tacrolimus ( $4 \mathrm{mg} /$ day), mycophenolate mofetil (MMF) ( $1 \mathrm{~g}$ x 2/day), and prednisone $(7.5 \mathrm{mg} /$ day). Eight years after renal transplantation, he presented with watery diarrhea, nausea and vomiting starting 15 days before consulting (September 25th, 2014). Physical examination revealed asthenia, weight loss $(6 \mathrm{Kg})$, hypotension, dry mouth, and acute renal failure (glomerular filtration rate [GFR]:
$30 \mathrm{ml} / \mathrm{min} / 1.73 \mathrm{~m}^{2}$ ). The patient reported no recent travel or contact with swimming pool water, nondrinking water or farm animals, but admitted to own a dog. No other family member experienced diarrhea.

Patient \#2 was a 64-year-old man of Malian origin who had lived in France for 40 years and undergone transplantation at the age of 62 for chronic renal failure secondary to glomerulonephritis. Immunosuppressive treatment consisted of tacrolimus (7 mg x 2/day), MMF (750 $\mathrm{mg} \times 2 /$ day), and prednisone (10 $\mathrm{mg} /$ day). Two years and 4 months following renal transplantation, he presented with watery diarrhea and abdominal pain lasting for 15-20 days (starting September 26th, 2014). Physical examination revealed weight loss $(13 \mathrm{Kg})$, esophageal pain, and acute renal failure (GFR: $36 \mathrm{~mL} /$ $\mathrm{min} / 1.73 \mathrm{~m}^{2}$ ). The patient also presented leucopenia and neutropenia, initially attributed to an overdose of tacrolimus. He reported no previous contact with nondrinking water, swimming pool water or farm animals, but had travelled to Mali for 2 months shortly before the onset of diarrhea. No other person of his family experienced diarrhea.

Patient \#3 was a 34-year-old man of Kosovar origin who underwent transplantation aged 24-year-old for an undetermined reason. Acute transplant rejection 2 years later led to a second transplantation in September, 2014. Immunosuppressive treatment consisted of tacrolimus (6 mg x 2/day), MMF (750 mg x 2/day), and prednisone ( $25 \mathrm{mg} /$ day). Ten days following the second renal transplantation (September 21th, 2014), the patient exhibited watery diarrhea and abdominal pain. Physical examination indicated weight loss $(10 \mathrm{Kg})$ and acute renal failure (GFR: $16 \mathrm{ml} / \mathrm{min} / 1.73 \mathrm{~m}^{2}$ ). The patient, who reported no contact with non-drinking water, swimming pool water or farm animals, had travelled to Kosovo for 1 month before transplantation. His 2-year-old daughter also presented with diarrhea from an unknown cause that lasted for 3 days. No stool analyses were done for the daughter.

\section{Parasitological investigations}

For all three patients, stool examinations performed at the first consultation revealed the presence of Cryptosporidium oocysts, using a modified Ziehl-Neelsen staining method (5-10 oocysts/slide, $>100$ oocysts/slide, and 1-5 oocysts/slide for cases \#1, \#2, and \#3, respectively). All stool samples were negative for the bacteria Clostridium difficile, Salmonella, Shigella but also for rotavirus and norovirus, and for parasites Giardia and microsporidia.

DNA was extracted from the stool samples using a NucliSENS easyMAG device (bioMérieux, Marcy l'Etoile, France) [17]. Briefly, it consisted of adding $400 \mathrm{mg}$ of stool samples to $1 \mathrm{~mL}$ of NucliSENS lysis buffer in a tube containing ceramic beads (lysing matrix D; MP Biomedicals, 
Illkirch, France), disrupted in a FastPrep-24 grinder (MP Biomedicals) at maximum power for $1 \mathrm{~min}$. After $10 \mathrm{~min}$ of incubation at room temperature to ensure complete lysis, the tubes were centrifuged at $10,000 \times g$ for $10 \mathrm{~min}$ and extraction was performed with $250 \mu \mathrm{L}$ of supernatant. Elution was performed at $70{ }^{\circ} \mathrm{C}$ with $100 \mu \mathrm{L}$ of elution buffer. An in-house real-time polymerase chain reaction (PCR) assay was set up to enable the detection and identification of the most common Cryptosporidium species/genotypes [18]. To this end, we used a single reaction tube with fluorescence-labelled probes for the real-time detection of Cryptosporidium, in addition to melting curve analyses of PCR products to differentiate between the Cryptosporidium species/genotypes. We conducted the amplification of a 258 bp DNA fragment located in the $18 \mathrm{~S}$ ribosomal ribonucleic acid (rRNA) gene (GenBank accession n'L16996; positions 80 to 337) using the following primers: Cry80F: 5'-GTTAAACTGCRAA TGGCT-3'; Cry337R: 5'-CGTCATTGCCACGGTA-3'. The CryAnch-labelled hybridization probe (5'-CCGTCTA AAGCTGATAGGTCAGAAACTTGAATG-fluorescein-3') hybridizes in a region that is conserved among all Cryptosporidium species and the CrySens labelled hybridization probe (5'-LCRed640-GTCACATTAATTGTGATCCGTAA AG-3') hybridizes in a polymorphic region (nucleotides 260 to 264) with various mismatches. Thermocycling and fluorescence detection were performed by means of a LightCycler 2.0 system (Roche Diagnostics) in a final volume of $20 \mu \mathrm{L}$, using a Roche LC Faststart DNA Master HYPROBE (Roche Diagnostics) with $0.5 \mu \mathrm{M}$ of each primer, $0.2 \mu \mathrm{M}$ of hybridization probe, $0.5 \mathrm{U}$ of UNG (Roche Diagnostics), and $5 \mu \mathrm{L}$ of extracted DNA. After applying $95{ }^{\circ} \mathrm{C}$ for $10 \mathrm{~min}$, amplification was commenced consisting of 50 cycles of 10 -sec denaturation at $95{ }^{\circ} \mathrm{C}, 15 \mathrm{sec}$ of annealing at $50{ }^{\circ} \mathrm{C}$ (with a touchdown protocol beginning at $60{ }^{\circ} \mathrm{C}$ ), and $15 \mathrm{sec}$ of elongation at $72{ }^{\circ} \mathrm{C}$. The fluorescent signal $(640 \mathrm{~nm})$ was detected following the annealing step of each cycle. Species/genotypes differentiation was based on differences in the melting temperatures of the PCR-probe complexes, which were determined based on the extent of complementation of the probes to the target strand of the PCR product. For the melting curve analysis, a quick denaturation step was performed at $95{ }^{\circ} \mathrm{C}$ followed by a 30 -sec annealing step from $45{ }^{\circ} \mathrm{C}$ to $80^{\circ} \mathrm{C}$ (ramp-up rate: $0.1{ }^{\circ} \mathrm{C} / \mathrm{s}$ ), with continuous detection throughout the ramp up. The technique was validated using Cryptosporidium DNA of a stool collection already characterized at the genus level and positive controls for C. parvum and C. hominis [12].

The five predominant human pathogenic Cryptosporidium species were identified based on their melting curve profiles $\left(61.9{ }^{\circ} \mathrm{C}, 53.8{ }^{\circ} \mathrm{C}, 48.8{ }^{\circ} \mathrm{C}, 56.7^{\circ} \mathrm{C}\right.$, and $51.8^{\circ} \mathrm{C}$ for C. parvum, C. hominis, C. felis, C. meleagridis, and C. canis, respectively). Given that $C$. cuniculus, an emergent human species, possesses the same melting curve profile as that of C. hominis, with both species exhibiting the same DNA sequence at the hybridization probe locus, all isolates identified as $C$. hominis were then sequenced to differentiate C. hominis from C. cuniculus.

For sub-genotyping analysis, DNA samples were subjected to amplification of an 850-bp fragment of the gp60 gene using a nested PCR method [19]. The total volume of PCR mixture was $50 \mu \mathrm{L}$, containing $5 \mu \mathrm{L}$ of DNA for the primary PCR or $5 \mu \mathrm{L}$ of the primary PCR products, primers (outer primers: AL3531 and AL3535; inner primers: AL3432 and AL3534) at a concentration of $0.4 \mu \mathrm{M}, 0.2 \mathrm{mM}$ deoxyribonucleotide triphosphate mix, and $1.25 \mathrm{U}$ of DreamTaq DNA polymerase. Each PCR reaction was subjected to 40 cycles of 30 s denaturation at $95{ }^{\circ} \mathrm{C}, 60 \mathrm{~s}$ annealing at $55^{\circ} \mathrm{C}$, and 60 s extension at $72{ }^{\circ} \mathrm{C}$, with an initial 5 min denaturation at $95{ }^{\circ} \mathrm{C}$ and a final $10 \mathrm{~min}$ extension at $72{ }^{\circ} \mathrm{C}$. PCR products were visualized by electrophoresis on an ethidium bromide stained $2 \%$ agarose gel electrophoresis. Amplicons were purified and sequenced in both directions with the forward and reverse primers used in the secondary PCR at a concentration of $0.32 \mu \mathrm{M}$. Sequencing was performed using a BigDye Terminator v3.1 Cycle Sequencing Kit (Applied Biosystems, USA) and an ABI PRISM 3100 Genetic Analyzer (Applied Biosystems, USA). We analyzed the quality of the generated electrophoregrams from each strand using 4Peaks software and compared them with those available in the GenBank database using the basic local alignment search tool. Subtype assignment was based on the number of trinucleotide repeats (TCA, TCG or TCT) in the coding for serine [20].

\section{Results}

For Patient \#1, genotyping revealed a C. felis infection. For Patient \#2, genotyping revealed $C$. hominis sub-genotype IaA13. For Patient \#3, the $C$. parvum sub-genotype IIaA13G1R2 was identified.

\section{Treatment}

All three patients were treated with nitazoxanide (500 mg x 2/day for 14 days). For Patient \#1, the stools tested negative 2 weeks after treatment initiation, with no recurrence of diarrhea observed 4 months after the first episode. For Patient \#2, a reduction of tacrolimus was initiated and the diarrhea regressed 8 days after treatment initiation, although 3 months after therapy was started, his stools still tested positive. A second administration of nitazoxanide was thus prescribed and we requested a stool sample from his daughter for testing. One month after the second treatment course, his stools were tested negative for Cryptosporidium oocysts. For Patient \#3, tacrolimus was also reduced and his diarrhea 
was regressing 1 month after treatment initiation. Four months after the second treatment course, his stools were tested negative for Cryptosporidium oocysts.

\section{Conclusions}

We report here a series of nearly concomitant cases of acute symptomatic cryptosporidiosis in three renal transplant patients attending the same outpatient unit of a Nephrology Department. The patients' consultations records in the Nephrology department showed that they could have been in contact in July 2014. This possibility of contact before the onset of symptoms suggesting a possible nosocomial infection requires a genotyping to explore this hypothesis. In these patients, Cryptosporidium species and gp60 genotypes, which were determined to document a possible outbreak, provided no evidence of nosocomial transmission.

As our report demonstrates, the detection of three different Cryptosporidium species in three cryptosporidiosis patients excluded the possibility of nosocomial transmission in the Nephrology unit, where renal transplant patients frequently consult and come into contact with each other. Our findings highlight the risk of symptomatic cryptosporidiosis in immunosuppressed renal transplant patients. In 2014, nine out of ten patients with cryptosporidiosis diagnosed by the medical Parasitology and Mycology laboratory of the Strasbourg University Hospital were renal transplant patients (unpublished data). In a pediatric renal transplantation unit, Cryptosporidium spp. was confirmed as the principal cause of diarrhea in patients between 6 months and 12 years of age following transplantation. In Poland and India, the prevalence of Cryptosporidium spp. in renal transplant patients was reported to be 18.8 and $20 \%$, respectively [21, 22]. Cryptosporidium spp. infections were more commonly associated with profuse watery diarrhea in solid-organ recipients than in immunocompetent patients [21, 23, 24]. Our patients undergoing combined immunosuppressive therapies exhibited watery diarrhea for several weeks before consulting, suggesting that the prevalence of Cryptosporidium spp. infections is probably underestimated in renal transplant units where screening of patients with diarrhea is not routinely performed. In all three of our patients, the symptoms completely resolved within 8 days to 1 month, in line with previous reports of slower recovery duration compared to immunocompetent patients in whom diarrhea symptoms usually cease after 10 to 15 days without treatment $[3,16]$. Considering the role of immunosuppression in the appearance and persistence of cryptosporidiosis, we opted to reduce the immunosuppressive regimen in two of our patients, which, in association with the anticryptosporidial agent, could prove an effective method in reducing both duration and severity of symptoms $[3,12,25]$.

C. felis cryptosporidiosis (patient \#1) is rarely diagnosed in France (4.8 \% of all cases between 2006 and 2009 vs., 54 \% for C. parvum and $36 \%$ for C. hominis) [5]. No contact with cats was reported, in agreement with previous reports showing that cat ownership is not a significant risk factor for $C$. felis infection and that $C$. felis host specificity is not very strict, since it was observed in cats, cattle and humans, thus rendering it often difficult to determine the source of infection $[5,26,27]$.

C. hominis infection observed in Patient \#2, is prevalent worldwide, and especially in developing areas, with similar incidences to those of $C$. parvum infection in most European countries, but less frequently reported than $C$. parvum infection in France and the Middle-East area [20, 24-29]. Travel-related cryptosporidiosis and small family outbreaks have been frequently associated with $C$. hominis infection, consistent with the onset of symptoms during our patient's trip to Africa [5]. To the best of our knowledge, human cases of the $C$. hominis IaA13 sub-genotype have only been reported in Australia, but reports of the $C$. hominis genotypes present in Africa are scarce [30].

C. parvum, the predominant species in French cryptosporidiosis patients, was detected in Patient \#3 [5]. The C. parvum IIaA13G1R2 genotype had previously been reported in Sweden and Germany with no identification of the mode of contamination [31].

Our findings confirm the need to consider cryptosporidiosis as a significant cause of acute persistent watery diarrhea in immunocompromised kidney transplanted patients. In hospitals or day-care centers, renal transplant patients should be informed in order to minimize risk of infection by handwashing and avoiding contact with young pets, infected people and swimming pools. Moreover, in renal transplant unit, patient with prolonged diarrhea should be tested for Cryptosporidium and isolated $[14,15]$. Risk of diarrhea due to Cryptosporidium being high for kidney transplant patients, species identification by molecular biology is important. First, to eliminate a possible nosocomial infection in patients who will be often in contact during consultations in the nephrology department; second, to determine the source of contamination (notably animal) and eliminate it to prevent any subsequent recontamination.

\footnotetext{
Abbreviations

MMF, mycophenolate mofetil; GFR, glomerular filtration rate; PCR, polymerase chain reaction; rRNA, ribosomal ribonucleic acid

\section{Acknowledgments}

The authors wish to thank the following contributors: ANOFEL Cryptosporidium National Network: Accoceberry I CHU Bordeaux, Agnamey P CHU Amiens, Angoulvant A CHU Bicêtre Paris, Aubert D CHU Amiens,
} 
Belkhadi G CHU St Antoine, Paris., Berry A. CHU Toulouse, Blanchet D CHU Cayenne, Bonhomme J CHU Caen, Botterel F CHU Creteil, Bougnoux ME CHU Necker, Paris, Brunet J CHU Strasbourg, Buffet P CHU Pitié, Paris, Dalle F CHU Dijon, Dannaoui E HEGP, Paris., Darde ML CHU Limoges, De Gentile L.CHU Angers, Debourgogne A. CHU Nancy, Debruyne M (Cerba, Paris), Degeilh B CHU Rennes, Demar M CHU Cayenne, Desbois N CHU Fort de France, Desoubeaux G CHU Tours, Delaunay P CHU Nice, Flori P CHU St Etienne, Gargala G CHU Rouen, Goubard A Biomnis Paris, Grenouillet F CHU Besancon, Hamane S CHU St Louis, Paris, Houze S CHU Bichat, Paris, Jamet D CHU Brest, Kapel N CHU Pitié, Paris, Labbe F CH Le Havre, Lemeteil D Lab. St Valéry en Caux, Magne D CHU St Antoine Paris, Marty P CHU Nice, Menotti J CHU St Louis, Paris, Million L CHU Besançon, Morelle C CHU Montpellier, Morio F CHU Nantes, Murat LB CHU Grenoble, Nevez G CHU Brest, Nicolas M CHU Guadeloupe, Poirier P CHU Clermont-Ferrand, Rabodonirina M CHU Lyon, Rodier MH CHU Poitiers, Sautour M CHU Dijon, Thellier M CHU Pitié, Paris, Totet A CHU Amiens, Valentin A CHU Toulouse, Villena I CHU Reims, and Yera H CHU Cochin, Paris.

\section{Funding}

No funding was obtain for this study.

\section{Availability of data and materials}

All the data supporting your findings is contained within the manuscript.

\section{Authors' contributions}

$J B, B P, L F$, EC were responsible for data analysis, management of data and wrote the manuscript. JPL, MS, FD, AWP, RR, AA helped in manuscript revision. SV, CM, CBD, SC, BM conducted clinical investigation and helped in manuscript revision. All authors read and approved the final manuscript.

\section{Competing interests}

The authors declare that they have no competing interests.

\section{Consent for publication}

Consent of each patient was obtained for the clinical data presented in this article.

\section{Ethics approval and consent to participate}

Not Applicable.

\section{Author details}

'Laboratoire de Parasitologie et de Mycologie Médicale, Plateau Technique de Microbiologie, Hôpitaux Universitaires de Strasbourg, 1 place de l'Hôpital, BP 426, F-67091 Strasbourg cedex, France. ${ }^{2}$ Institut de Parasitologie et Pathologie Tropicale, EA 7292, Fédération de Médecine Translationnelle, Université de Strasbourg, 3 rue Koeberlé, F-67000 Strasbourg, France. ${ }^{3}$ Laboratoire de Parasitologie et de Mycologie, Plateau Technique de Biologie du CHU Dijon, 2 rue Angélique Ducoudray, BP 37013, F-21070 Dijon cedex, France. ${ }^{4}$ UMR 1347, Université de Bourgogne, 17 rue de Sully, F-21000 Dijon, France. ${ }^{5}$ Département de Néphrologie et Transplantation, Hôpitaux Universitaires de Strasbourg, 1 place de I'Hôpital, BP 426, F-67091 Strasbourg cedex, France. 'Laboratoire de Parasitologie-Mycologie, EA 3800, Centre Hospitalier Universitaire, Université de Rouen, 1, rue de Germont, F-76031 Rouen, France.

Received: 1 July 2015 Accepted: 8 June 2016

\section{Published online: 02 August 2016}

\section{References}

1. Baldursson S, Karanis P. Waterborne transmission of protozoan parasites: review of worldwide outbreaks - an update 2004-2010. Water Res. 2011;45:6603-14.

2. Kotloff KL, Nataro JP, Blackwelder WC, Nasrin D, Farag TH, Panchalingam S, Wu Y, Sow SO, Sur D, Breiman RF, Faruque AS, Zaidi AK, Saha D, Alonso PL, Tamboura B, Sanogo D, Onwuchekwa U, Manna B, Ramamurthy T, Kanungo S, Ochieng JB, Omore R, Oundo JO, Hossain A, Das SK, Ahmed S, Qureshi S, Quadri F, Adegbola RA, Antonio M, Hossain MJ, Akinsola A, Mandomando I, Nhampossa T, Acacio S, Biswas K, O'Reilly CE, Mintz ED, Berkeley LY, Muhsen K, Sommerfelt H, Robins Browne RM, Levine MM. Burden and aetiology of diarrhoeal disease in infants and young children in developing countries (the Global Enteric Multicenter Study, GEMS): a prospective, case-control study. Lancet. 2013;382:209-22.

3. Checkley W, White Jr AC, Jaganath D, Arrowood MJ, Chalmers RM, Chen XM, Fayer R, Griffiths JK, Guerrant RL, Hedstrom L, Huston CD, Kotloff KL,
Kang G, Mead JR, Miller M, Petri Jr WA, Priest JW, Roos DS, Striepen B, Thompson RC, Ward HD, Van Voorhis WA, Xiao L, Zhu G, Houpt ER. A review of the global burden, novel diagnostics, therapeutics, and vaccine targets for cryptosporidium. Lancet Infect Dis. 2015;15:85-94.

4. Fayer R, Morgan U, Upton SJ. Epidemiology of Cryptosporidium: transmission, detection and identification. Int J Parasitol. 2000;30:1305-22.

5. Network ACN. Laboratory-based surveillance for Cryptosporidium in France, 2006-2009. Euro Surveill. 2010;15:19642.

6. Pesson B, Brunet J, Abou Bacar A, Pfaff A, Zuccala C, Candolfi E. Coprologie parasitaire : bilan des examens au CHU de Strasbourg de 2011 à 2013. Feuillets de Biologie. 2015;324:33-40.

7. Colussi O, Rouen A, Seksik P, Cosnes J, Beaugerie L, Sokol H. Acute cryptosporidiosis as a cause of sudden recurrence of digestive symptoms in patients with Crohn's disease. J Crohns Colitis. 2010;4:669-70.

8. Feng Y, Wang L, Duan L, Gomez-Puerta LA, Zhang L, Zhao W, Hu J, Zhang $\mathrm{N}$, Xiao L. Extended outbreak of cryptosporidiosis in a pediatric hospital, China. Emerg Infect Dis. 2012;18:312-4.

9. Bruce BB, Blass MA, Blumberg HM, Lennox JL, del Rio C, Horsburgh Jr CR. Risk of Cryptosporidium parvum transmission between hospital roommates. Clin Infect Dis. 2000;31:947-50.

10. MacKenzie WR, Schell WL, Blair KA, Addiss DG, Peterson DE, Hoxie NJ, Kazmierczak JJ, Davis JP. Massive outbreak of waterborne cryptosporidium infection in Milwaukee, Wisconsin: recurrence of illness and risk of secondary transmission. Clin Infect Dis. 1995;21:57-62.

11. Roefer P, Monscvitz JT, Rexing DJ. The Las Vegas cryptosporidiosis outbreak. JAWWA. 1996:88:95-106.

12. Dalle F, Roz P, Dautin G, Di-Palma M, Kohli E, Sire-Bidault C, Fleischmann MG, Gallay A, Carbonel S, Bon F, Tillier C, Beaudeau P, Bonnin A. Molecular characterization of isolates of waterborne Cryptosporidium spp. collected during an outbreak of gastroenteritis in South Burgundy, France. J Clin Microbiol. 2003;41:2690-3.

13. Xiao L, Feng Y. Zoonotic cryptosporidiosis. FEMS Immunol Med Microbiol. 2008;52:309-23.

14. Hunter PR, Nichols G. Epidemiology and clinical features of Cryptosporidium infection in immunocompromised patients. Clin Microbiol Rev. 2002;15:145-54.

15. Chalmers RM, Davies AP. Minireview: clinical cryptosporidiosis. Exp Parasitol. 2010;124:138-46.

16. Aulagnon F, Scemla A, DeWolf S, Legendre C, Zuber J. Diarrhea after kidney transplantation: a new look at a frequent symptom. Transplantation. 2014; 98:806-16.

17. Mary C, Chapey E, Dutoit E, Guyot K, Hasseine L, Jeddi F, Menotti J, Paraud C, Pomares C, Rabodonirina M, Rieux A, Derouin F. ANOFEL Cryptosporidium National Network. Multicentric evaluation of a new real-time PCR assay for quantification of Cryptosporidium spp. and identification of Cryptosporidium parvum and Cryptosporidium hominis. J Clin Microbiol. 2013;51:2556-63.

18. Limor JR, Lal AA, Xiao L. Detection and differentiation of Cryptosporidium parasites that are pathogenic for humans by real-time PCR. J Clin Microbiol. 2002:40:2335-8.

19. Alves M, Xiao L, Sulaiman I, Lal AA, Matos O, Antunes F. Subgenotype analysis of Cryptosporidium isolates from humans, cattle and zoo ruminants in Portugal. J Clin Microbiol. 2003:41:2744-7.

20. Sulaiman IM, Hira PR, Zhou L, Al-Ali FM, Al-Shelahi FA, Shweiki HM, lqbal J, Khalid N, Xiao L. Unique endemicity of cryptosporidiosis in children in Kuwait. J Clin Microbiol. 2005;43:2805-9.

21. Ok UZ, Cirit M, Uner A, Ok E, Akcicek F, Basci A, Ozcel MA. Cryptosporidiosis and blastocystosis in renal transplant recipients. Nephron. 1997;75:171-4.

22. Udgiri N, Minz M, Kashyap R, Heer M, Gupta CS, Mohandas K, Minz RW, Malla N. Intestinal cryptosporidiasis in living related renal transplant recipients. Transplant Proc. 2004;36:2128-9.

23. Arslan H, Inci EK, Azap OK, Karakayali H, Torgay A, Haberal M. Etiologic agents of diarrhea in solid organ recipients. Transpl Infect Dis. 2007;9:270-5.

24. Raja K, Abbas Z, Hassan SM, Luck NH, Aziz T, Mubarak M. Prevalence of cryptosporidiosis in renal transplant recipients presenting with acute diarrhea at a single center in Pakistan. J Nephropathol. 2014;3:127-31.

25. Collinet-Adler S, Ward HD. Cryptosporidiosis: environmental, therapeutic, and preventive challenges. Eur J Clin Microbiol Infect Dis. 2010;29:927-35.

26. Glaser CA, Safrin S, Reingold A, Newman TB. Association between Cryptosporidium infection and animal exposure in HIV-infected individuals. J Acquir Immune Defic Syndr Hum Retrovirol. 1998;17:79-82.

27. Guyot K, Follet-Dumoulin A, Lelievre E, Sarfati C, Rabodonirina M, Nevez G, Cailliez JC, Camus D, Cei-Cas E. Molecular characterization 
ofCryptosporidium isolates obtained from humans in France. J Clin Microbiol. 2001;39:3472-80.

28. Gatei W, Das P, Dutta P, Sen A, Cama V, Lal AA, Xiao L. Multilocus sequence typing and genetic structure of Cryptosporidium hominis from children in Kolkata, India. Infect Genet Evol. 2007;7:197-205.

29. Zintl A, Ezzaty-Mirashemi M, Chalmers RM, Elwin K, Mulcahy G, Lucy FE, DE Waal T. Longitudinal and spatial distribution of GP60 subtypes in human cryptosporidiosis cases in Ireland. Epidemiol Infect. 2011;139:1945-55.

30. Waldron LS, Dimeski B, Beggs PJ, Ferrari BC, Power ML. Molecular epidemiology, spatiotemporal analysis, and ecology of sporadic human cryptosporidiosis in Australia. Appl Environ Microbiol. 2011;77:7757-65.

31. Silverlås C, Bosaeus-Reineck $H$, Näslund K, Björkman C. Is there a need for improved Cryptosporidium diagnostics in Swedish calves? Int J Parasitol. 2013;43:155-61.

Submit your next manuscript to BioMed Central and we will help you at every step:

- We accept pre-submission inquiries

- Our selector tool helps you to find the most relevant journal

- We provide round the clock customer support

- Convenient online submission

- Thorough peer review

- Inclusion in PubMed and all major indexing services

- Maximum visibility for your research

Submit your manuscript at www.biomedcentral.com/submit
Biomed Central 